\title{
Mitochondrial DNA from the scallop Pecten maximus: an unusual polymorphism detected by restriction fragment length polymorphism analysis
}

\author{
ALI RIGAA† \\ $\ddagger$ Centre de Génétique Moléculaire, CNRS, F - 91198 Gif sur Yvette Cedex, France \\ and §Station Biologique, 29182 Concarneau, France
}

\begin{abstract}
We present an analysis of mitochondrial DNA diversity within the scallop Pecten maximus. Twenty-seven individuals of Pecten maximus were sampled from three populations from the west coast of Brittany (France) and their mtDNA assayed for restriction site polymorphism. Thirty-four variable and conserved cleavage sites have been mapped. They occur in the coding region as well as in the noncoding one, which has also previously been shown to be variable in length. Nucleotide divergence between two $P$. maximus mtDNA types can reach 3.4 per cent and the nucleotide diversity is 1 per cent. Data using seven restriction endonucleases clearly distinguished 27 genotypes; each individual possessed a unique mitochondrial genotype. Phylogenies derived from mtDNA restriction analysis are not concordant with data on reproductive behaviour or ecological studies. The three populations sampled present similar distributions of the different mitochondrial genotypes, although the scallop stock of the Bay of Saint Brieuc is considered, from physiological parameters, to be genetically distinct from all other populations. Therefore, we suggest that $P$. maximus should fall into category IV of phylogeographical pattern, i.e. continuous mtDNA genotypes with a high gene flow.
\end{abstract}

Keywords: mtDNA, Pecten maximus, RFLP, unusual polymorphism.

\section{Introduction}

The most widely encountered representative of the family Pectinidea (Mollusca, Bivalvia) on the western coast of France is the scallop, Pecten maximus, a commercially important species. This species is restricted by suitable habitat and is capable of forming sustainable yields, although prone to overfishing.

Both natural and hatchery-reared populations of $P$. maximus have been the subject of genetic studies based on protein electrophoresis (Beaumont, 1991; Beaumont et al., 1993), reproductive cycle (Cochard \& Devauchelle, 1993) and variations in ecological reproduction (Mackie \& Ansell, 1993). The most interesting of all these studies is the specific reproductive behaviour of the scallop originating from the Bay of Saint Brieuc of the Brittany area. The $P$.

$\dagger$ Present address: University of Utah, Medical Center, Division of Hematology-Oncology, 50 North Medical Drive, Salt Lake City, Utah 84132, U.S.A.

${ }^{*}$ Correspondence. E-mail: monnerot@cgm.cnrs-gif.fr maximus individuals native to St Brieuc exhibit a well-synchronized and unique massive spawning during a short period in the summer. Spawning of scallops from other populations, including those of neighbouring areas (e.g. Rade of Brest), is much less synchronized and extends over a long period (Paulet et al., 1988). It was proposed that genetic as well as environmental parameters were responsible for differences in reproductive behaviour. In contrast, data on allozymes suggest a high genetic similarity among all the populations, including those transplanted at spat or juvenile stage from Scottish and Irish areas to St Brieuc Bay (Beaumont et al., 1993).

Biochemical methods such as protein electrophoresis have contributed greatly to the understanding of population genetic and phylogenetic relationships (Avise et al., 1979). Recently analyses involving the restriction enzyme assay of mitochondrial DNA have increased dramatically. Indeed, mtDNA offers some major advantages over the bulk of the cell nuclear DNA. Because it is predominantly transmitted through the oocyte cytoplasm, it 
is maternally inherited (Giles et al., 1980) without undergoing the gene shuffling that can obscure the evolutionary trail of nuclear genes. However, biparental transmission of mtDNA to the eggs has been rigorously assessed in Mytilus, but no recombination has been detected between different mtDNA lineages (Zouros et al., 1992, 1994a,b; Skibinski et al., 1994). This peculiar situation does not hold for $P$. maximus (Rigaa, 1994). Although in invertebrates mtDNA does not evolve faster than nuclear DNA (Monnerot et al., 1990), its variations remain an important source of information for relationships between populations or species.

The purpose of this investigation was to assess mtDNA restriction site polymorphism (through RFLP) in three populations of $P$. maximus, collected from Brittany on the west coast of France, in order to explore any correlations between mtDNA variations and the reproductive behaviour of individuals originating from different geographical sites. In addition, the survey may shed some light on the evolutionary relationships of scallop populations.

\section{Materials and methods}

The scallop (Pecten maximus) individuals involved in this study originated from three localities (Fig. 1) in Brittany, France (Brest area, Saint Brieuc Bay and Glénan Islands). mtDNA was isolated individually from fresh muscle $(10-20 \mathrm{~g})$ and purified as previously described by Rigaa et al. (1993).

Restriction enzyme digestions were carried out to completion with seven endonucleases (AvaI, AvaII, $B c l \mathrm{I}, B g l \mathrm{II}, E c o$ RI, HindIII and HpaI) following the supplier's instructions. Products of digestion were end-labelled with a radioactive mixture of four

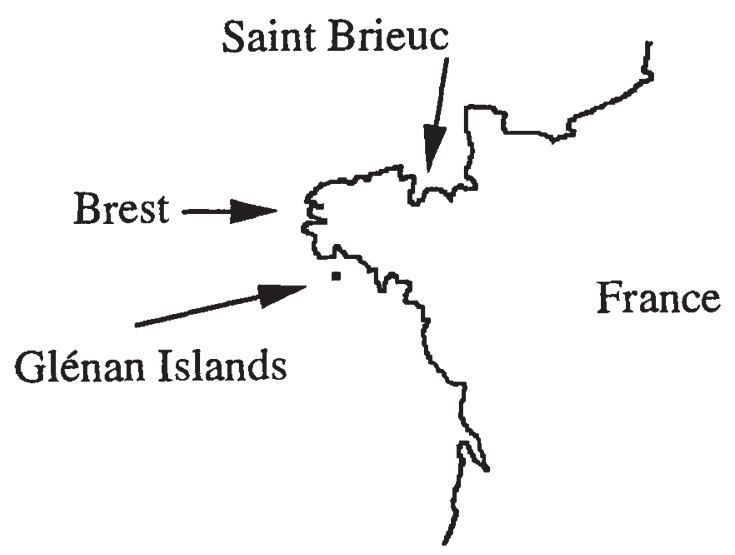

Fig. 1 Map of Brittany. The geographical origins of scallop Pecten maximus samples are indicated with arrows: Saint Brieuc Bay, Brest area and Glénan Islands.
dNTPs in the presence of DNA polymerase I (Klenow fragment). mtDNA fragments were then separated by electrophoresis on 1 per cent agarose and 6 per cent acrylamide gels and visualized by autoradiography. Mapping of the restriction sites for $A v a \mathrm{I}, B c l \mathrm{I}, B g l \mathrm{II}, E c o \mathrm{RI}, H i n \mathrm{dIII}$ and $H p a \mathrm{I}$ was by single and double digest analysis.

Phylogenetic relationships were determined using the PAUP program for maximum parsimony analysis (Swofford, 1990). The total number of minimal trees was determined by the branch and bound method. The minimal length tree found after 10 replicate random heuristic searches was taken as the initial upper boundary for the branch and bound search. In addition, a 50 per cent majority rule consensus tree was generated from 1000 bootstrap replicate heuristic searches. Nei nucleotide distances and standard errors were calculated using the RESTSITES program version 1.2 (Nei \& Miller, 1990).

\section{Results}

Seven endonucleases (AvaI, AvaII, BclI, BglII, EcoRI, HindIII and HpaI) were chosen, among the 23 assayed, to study the polymorphism of mtDNA from 27 specimens. Four base recognition cleavage site endonucleases were discarded because they yielded too many small fragments (less than $2 \mathrm{~kb}$ ), leading to poor resolution on gels. The different patterns obtained are shown in Table 1 (for AvaII) and in Fig. 2 (for the other enzymes, see further). A total of 40-56 fragments were scored per individual, resulting in a survey of 254 nucleotides on average, i.e. 1.2 per cent of the $21.6 \mathrm{~kb}$ as the modal size of the $P$. maximus mitochondrial genome (Rigaa et al., 1993).

Among these seven enzymes, AvalI reveals the most variable patterns (11), eight of them (D, E, F, G, H, I, J and K, Table 1) being found only once. $B g l I I, H p a I$ and HindIII are less polymorphic restriction endonucleases, each revealing only three rare patterns (Table 2).

Considering the data as a whole, the composite mtDNA genotype of each individual was determined (Table 2). Twenty-seven genotypes were observed for the 27 individuals sampled.

Mapping of polymorphic sites has been undertaken to estimate accurately the nucleotide divergence between the different mtDNA types. The numerous AvaII fragments did not permit a reliable mapping of the corresponding restriction sites by single and double digest analysis. The sites recognized by this restriction endonuclease were consequently discarded for further analysis. Figure 2 
Table 1 Restriction patterns for AvaII endonuclease obtained for Pecten maximus

\begin{tabular}{lcccccccccc}
\hline A & B & C & D & E & F & G & H & I & J & K \\
\hline L F & L F & L F & L F & L F & L F & L F & L F & L F & L F & L F \\
2550 & 2550 & 2550 & 2550 & 2550 & 2550 & 2550 & 2550 & 2550 & 2550 & 2550 \\
2450 & 2450 & 2450 & 2200 & 2450 & 2450 & 2450 & 2450 & 2450 & 2450 & 2450 \\
1500 & 1500 & 1500 & 1500 & 1350 & 1500 & 1500 & 1600 & 1500 & 1500 & 1800 \\
1350 & 1350 & 1350 & 1350 & $2 \times 1250$ & 1350 & 1350 & 1500 & 1350 & 1450 & 1600 \\
$2 \times 1250$ & $2 \times 1250$ & $2 \times 1250$ & $2 \times 1250$ & 1100 & $2 \times 1250$ & $2 \times 1250$ & 1350 & $2 \times 1250$ & $2 \times 1250$ & 1500 \\
1100 & 1100 & 1100 & 1100 & 1000 & 1100 & 1100 & $2 \times 1250$ & 1100 & 1100 & 1350 \\
1000 & 1000 & 800 & 800 & 900 & 800 & 1000 & 1100 & 1000 & 1000 & $2 \times 1250$ \\
500 & 500 & 500 & 500 & 600 & 500 & 970 & 1000 & 500 & 500 & 1100 \\
400 & 300 & 400 & 400 & 500 & 300 & 500 & 500 & 100 & 400 & 1000 \\
100 & $2 \times 100$ & 200 & 250 & 400 & 200 & 470 & 400 & & & 500 \\
& & 100 & 200 & 100 & $2 \times 100$ & 400 & 100 & & & 400 \\
& & & 100 & & & 100 & & & 100 \\
\hline
\end{tabular}

$\mathrm{LF}$, the largest fragment of each pattern; it depends on the total size of the mitochondrial genome. LF has the following sizes (in $\mathrm{kb}$ ) for the patterns: $\mathrm{A} \mathrm{Ss}=6.6, \mathrm{~A} \mathrm{~S}=8.2, \mathrm{~A} \mathrm{M}=9.7, \mathrm{~A} \mathrm{~L}=11.3$ and $\mathrm{A} \mathrm{Sl}=12.3$; $\mathrm{B} \mathrm{Ss}=6.6$ and $\mathrm{B} \mathrm{M}=9.7$; $\mathrm{C} \mathrm{S}=8.2$ and $\mathrm{C} \mathrm{M}=9.7$; $\mathrm{S}, \mathrm{E} \mathrm{S}, \mathrm{F} \mathrm{S}$ and $\mathrm{J} \mathrm{S}=8.2 ; \mathrm{G} \mathrm{I}=7.3 ; \mathrm{H} \mathrm{S}=6.6 ; \mathrm{I} \mathrm{M}=10.1 ; \mathrm{K} \mathrm{S}=4.7 \mathrm{~kb}$.

presents the relative location of $A v a \mathrm{I}, B c l \mathrm{I}, B g l \mathrm{II}$, EcoRI, HindIII and $H p a I$ restriction sites taking into account the length variability (Ss, S, I, M, L and Sl refer to the different molecule sizes as previously defined in Rigaa et al., 1993). The relative lack of restriction sites within the noncoding region is relevant to its nucleotide content (Rigaa et al., 1993), as in Drosophila (Solignac et al., 1986).

Twenty-three out of the 38 sites considered outside of the repeats were conserved in mtDNA from the 22 samples analysed completely and the remaining 15 sites were polymorphic, both conserved and polymorphic sites being regularly distributed all along this domain of the mtDNA molecule (Fig. 2).

One EcoRI polymorphic site was shown to be carried by every copy of the $1.6-\mathrm{kb}$ repeat unit present in the corresponding molecules (profile $\mathrm{C}$, Fig. 2) and consequently counted only once. The presence/absence of this site is independent of the size of the genome and thus of the number of the repeat units.

All but one AvaI polymorphic sites are located within the repeats area. Because they might lead to ambiguous interpretations arising from the repeat process they were not considered for either tree building or distance calculation.

Figure 3 represents a phylogenetic tree obtained from an analysis using Paup (Swofford, 1990). The displayed tree comprises a consensus of the 17 shortest length trees and illustrates the relationships between composite genotypes. Individuals from each population of $P$. maximus are not clearly clustered on the tree upon either the RFLP patterns, the sizes of the genomes or the geographical origins. The only two subdivisions include samples from Brest and St Brieuc with different genome sizes.

Nucleotide distances between individuals can reach $3.4 \pm 0.9$ per cent with $1.3 \pm 0.8$ per cent, $1.1 \pm 1.3$ per cent and $0.7 \pm 0.4$ per cent for the divergences (corrected values) Glénan-Brest, BrestSt Brieuc and Glénan-St Brieuc, respectively. The nucleotide diversities are, respectively, 0.6, 1 and 1.1 per cent for the populations from Glénan, Brest and Saint Brieuc, with 1 per cent as the overall value. The differences between the three populations are not significant (Fisher-Snedcor test).

\section{Discussion}

The mtDNA polymorphism for AvaI, AvaII, BclI, $B g l \mathrm{II}, E c o$ RI, HindIII and $H p a \mathrm{I}$ sites was examined in three scallop populations from different locations on the western coast of France: Brest area, Saint Brieuc Bay and Glénan Islands.

Two domains have been recognized previously in the $P$. maximus mitochondrial genome (Rigaa et al., 1993, 1995): a noncoding domain, in which variations in the copy number of a $1.6-\mathrm{kb}$ unit are responsible for an important length polymorphism; and a coding domain with no length variations. Nucleotide substitutions inferred from restriction site polymorphism and mapping appear to occur in both domains, without relationships with the size of the molecules. These two mutational phenomena, leading, respectively, to size and endonuclease cleav- 
age site polymorphisms, are likely to be independent.

In the noncoding region, the presence/absence of multiple sites, one on each repeat unit, can be interpreted by the copy of an original unit carrying the corresponding mutation. Alternatively, this can be caused by a homogenization of the repeat units after the occurrence of a mutation in one of them. Both proposals are in accordance with the concerted evolution concept (Solignac et al., 1986). As a consequence, estimates of nucleotide distances have to take into account only one mutation event at the locus considered: this has been done for EcoRI. The situation is more complex for some AvaI polymorphic sites within the repeats (Fig. 2) and homologous sites are difficult to appraise.
Fig. 2 Maps of the different mitochondrial types of Pecten maximus. The maps are based on the recognition sites for six restriction enzymes. The genome is linearized at the HpaI site located 104 nucleotides downstream from the beginning of the coding region. The fragment sizes are in $\mathrm{kb}$. For each set of maps the name of the enzyme considered is written at the top. For each type the first letter refers to differences in sites and the last one(s) to differences in length as already published: $\mathrm{Ss}=20$ $\mathrm{kb}, \mathrm{S}=21.6 \mathrm{~kb}, \mathrm{I}=22.2 \mathrm{~kb}, \mathrm{M}=23.2$ $\mathrm{kb}, \mathrm{L}=24.8 \mathrm{~kb}$ and $\mathrm{Sl}=25.8 \mathrm{~kb}$ (Rigaa et al., 1993). Bars with arrows stand for the 1.6-kb repeated units located in the unique length variable domain.

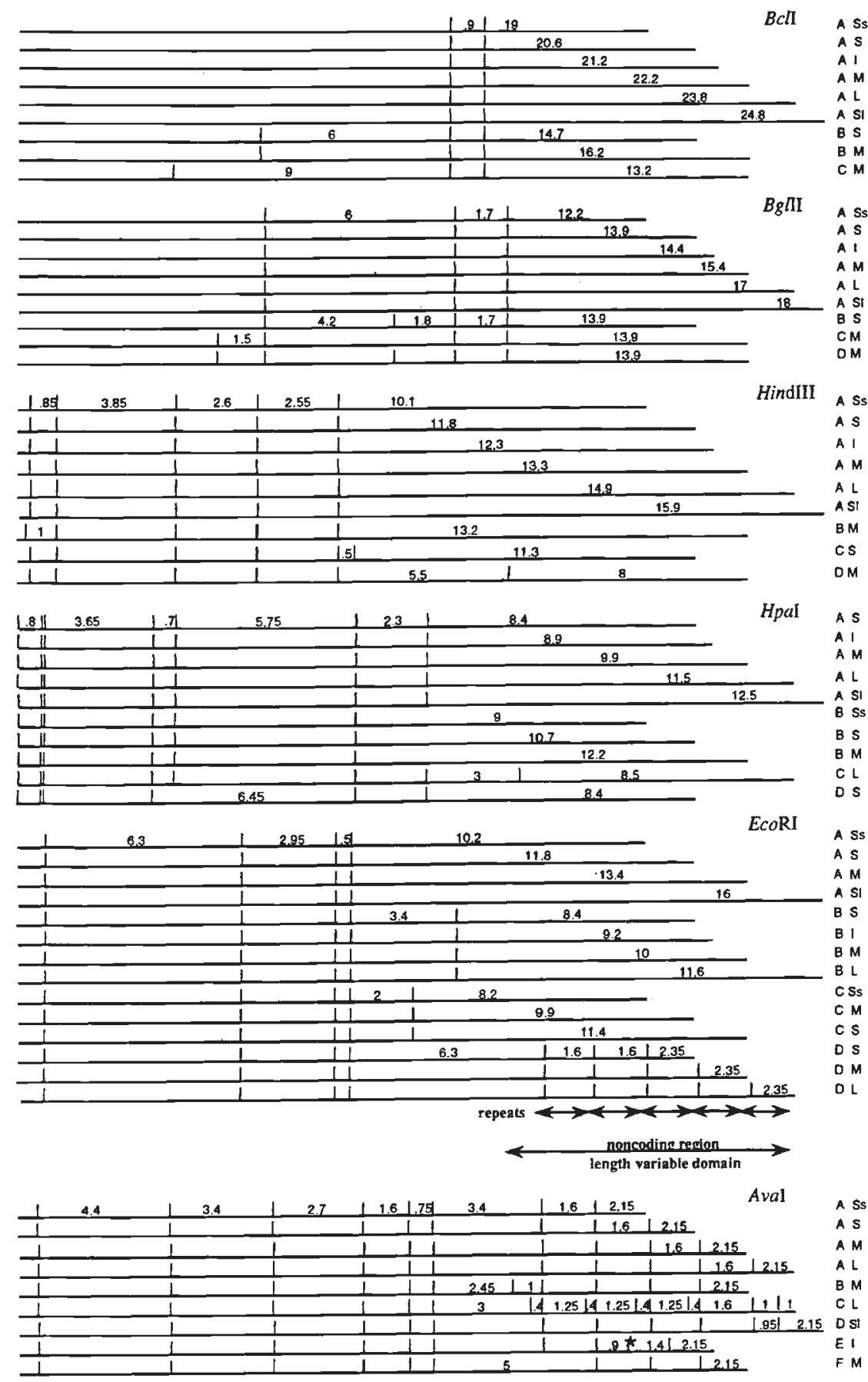


Table 2 Composite mtDNA genotypes observed in the three geographical samples of Pecten maximus. The entire mitochondrial genome sizes are referred to as: Ss, supershort; S, short; M, medium; I, intermediate; L, long; Sl, superlong. Individual number 6 is heteroplasmic for short and supershort mitochondrial genomes (Rigaa et al., 1993). An alphabetical character is assigned to each unique restriction pattern (see Table 1 and Fig, 2)

\begin{tabular}{|c|c|c|c|c|c|c|c|c|c|c|c|c|c|c|c|c|c|c|c|c|c|c|c|c|c|c|c|}
\hline $\begin{array}{l}\text { Individual } \\
\text { Size }\end{array}$ & 1 & 2 & 3 & 4 & 5 & 6 & 1 & 2 & 3 & 4 & 5 & 6 & 7 & 8 & 9 & 10 & 11 & 12 & 13 & 1 & 2 & 3 & 4 & 5 & 6 & 7 & 8 \\
\hline AvaI & ND & $\mathrm{A}$ & $\mathrm{A}$ & ND & A & A & $\mathrm{B}$ & A & $\mathrm{C}$ & A & $\mathrm{D}$ & A & $\mathrm{A}$ & A & $\mathrm{E}$ & $\mathrm{A}$ & A & $\mathrm{A}$ & A & A & A & ND & $\mathrm{F}$ & A & A & A & \\
\hline AvaII & $\mathrm{B}$ & $\mathrm{A}$ & $\mathrm{A}$ & $\mathrm{B}$ & A & D & A & A & $\mathrm{A}$ & A & A & A & $\mathrm{J}$ & $\mathrm{C}$ & $\mathrm{G}$ & $\mathrm{E}$ & $\mathrm{F}$ & A & $\mathrm{A}$ & $\mathrm{C}$ & $\mathrm{H}$ & $\mathrm{K}$ & $\mathrm{A}$ & $\mathrm{F}$ & $\mathrm{A}$ & I & A \\
\hline EcoRI & $\mathrm{C}$ & $\mathrm{B}$ & A & A & A & $\mathrm{C}$ & B & A & $\mathrm{D}$ & $\mathrm{B}$ & A & A & $\mathrm{A}$ & $\mathrm{C}$ & B & $\mathrm{A}$ & $\mathrm{C}$ & $\mathrm{D}$ & $\mathrm{D}$ & $\mathrm{C}$ & B & A & $\mathrm{D}$ & $\mathrm{C}$ & $\mathrm{B}$ & A & B \\
\hline HindIII & ND & $\mathrm{A}$ & $\mathrm{A}$ & ND & A & A & B & A & $\mathrm{A}$ & A & A & A & $\mathrm{A}$ & A & A & $\mathrm{A}$ & $\mathrm{A}$ & A & $\mathrm{A}$ & A & A & A & A & A & A & $\mathrm{D}$ & $\mathrm{C}$ \\
\hline HpaI & ND & A & $\mathrm{A}$ & ND & A & A & A & A & $\mathrm{C}$ & $\mathrm{D}$ & A & B & A & A & A & $\mathrm{A}$ & $\mathrm{A}$ & $\mathrm{A}$ & $A$ & A & A & A & $\mathrm{A}$ & A & A & B & $A$ \\
\hline
\end{tabular}

ND, patterns not determined.

Based on the restriction analysis of the mitochondrial genome, the sequence divergence of $P$. maximus mtDNA can be as high as 3.4 per cent (corrected value) with a nucleotide diversity of 1 per cent. Convergent losses or gains of restriction sites are not uncommon features of mtDNA evolution (Avise, 1991). Hypervariable restriction sites are identified by the fact that their states (loss or gain) occur in two or more of the mtDNA assemblages assayed (see patterns for $B g l \mathrm{II}$ ). This hypervariability leads to the impossibility of constructing a very parsimonious tree. mtDNA site polymorphism is thus greater in $P$. maximus than in most other scallops so far studied: Gjetvaj et al. (1992), in an analysis of six species (including $P$. maximus), report restriction site polymorphism only for Argopecten irradians; however, nothing is said about its frequency. The high level of polymorphism described here could arise from different rates of evolution within the Pectinidae family or from special features of $P$. maximus populations.

In spite of the existence of a large restriction site polymorphism of mtDNA from $P$. maximus, there is no clear evidence for site heteroplasmy. Such a phenomenon is not impossible, but probably occurs at low frequency. One species, Chlamys islandic, among the seven studied by Gjetvaj et al. (1992) exhibited site heteroplasmy for one individual among 119. Site heteroplasmy exists at high frequency in mussels (and other molluscan bivalves) and has been experimentally related to biparental mitochondrial inheritance (Fisher \& Skibinski, 1990; Hoeh et al., 1991; Zouros et al., 1992, 1994a,b; Skibinski et al., 1994). It so far seems that paternal inheritance is limited to the mussel family; it has been observed neither in Pecten maximus (this study) nor in other scallop species (Gjetvaj et al., 1992; Boulding et al., 1993; Repin \& Brykov et al., 1993). Thus, neither a high evolutionary rate nor paternal transmission can account for this unusual intraspecific diversity, the origin of which remains to be understood.

The organization of the genetic diversity revealed in our mtDNA assay does not reflect the fine-scale geographical patterns apparent from the reproductive behaviour of the three populations of $P$. maximus. Strong evidence has been reported to support genetic isolation of the population from Saint Brieuc (Paulet et al., 1988; Cochard \& Devauchelle, 1993). The St Brieuc native scallops have a very discrete reproductive period in the summer, in contrast to scallops in most other areas, which have spawn over a long period of the year. Mackie \& Ansell (1993) have concluded that important elements of the reproductive cycle are under genetic control and that the St Brieuc population, with its unique cycle, should be genetically distinct from other populations. However, genetic differentiation is evidenced by neither allozyme data (Beaumont et al., 1993) nor the RFLP analysis of mtDNA presented in this paper. Indeed, and contrary to earlier estimates, recent studies of intra- and interpopulational allozyme variability of $P$. maximus from areas in Ireland, Scotland and Brittany (Beaumont et al., 1993) have shown an overall deficiency of heterozygotes with no geographical differentiation. Although heterozygote deficiency is a common phenomenon in bivalves, it has been demonstrated 
to be accompanied by significant intra- and interpopulation differentiation for mitochondrial haplotypes in mussels (Blot et al., 1990; Karakausis \& Skibinski, 1992).

The lack of macrogeographical structuration of mtDNA haplotypes seems to be a feature of species with high gene flow. Therefore, $P$. maximus should be placed in category IV of the phylogeographical pattern as described by Avise et al. (1987), i.e. continuous mtDNA genotypes through geographical regions. This leads to the conclusion that the analysed populations of $P$ maximus constitute a single genetic pool with regard to their mitochondrial genomes.

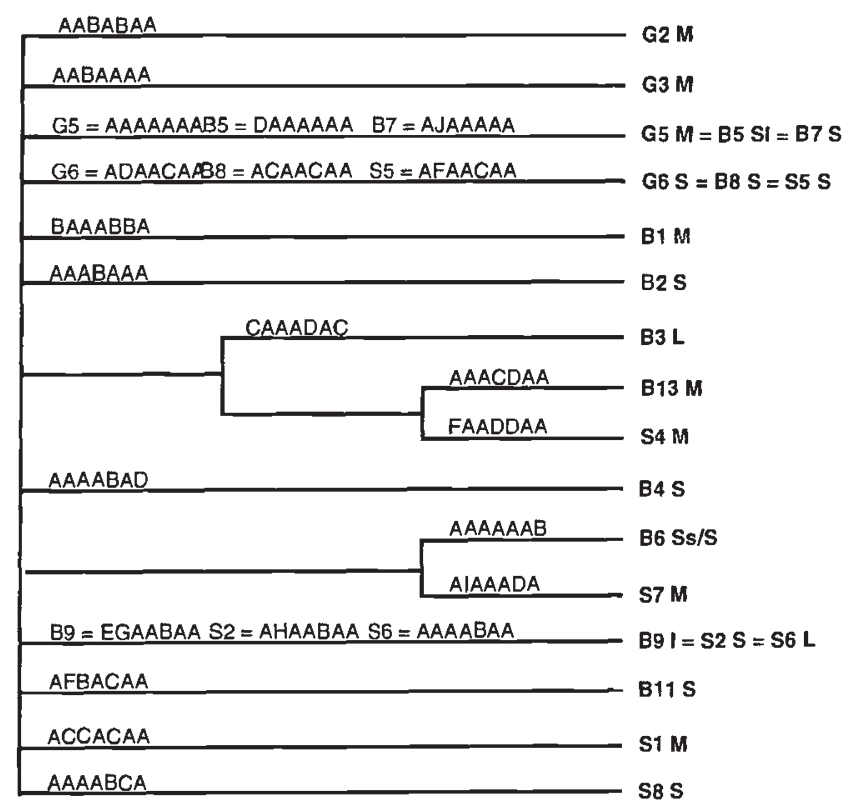

Fig. 3 Phylogenetic tree obtained from maximum parsimony analysis using PAUP. It is based on the individual polymorphic restriction sites mapped in Fig. 2 except that of $A v a \mathrm{I}$ to avoid any ambiguity. A branch and bound search retained the 17 shortest trees. The tree displayed represents a consensus of those shortest length trees. The tree has a consistency index (CI) of 0.824 and homoplasmy index (HI) of 0.176. Excluding uninformative characters, $\mathrm{CI}=0.7$ and $\mathrm{HI}=0.3$. The retention index $(\mathrm{RI})=0.769$. The first letter indicates the geographical origin of the specimen: G, the Glénan Islands; B, Brest area; S, Saint Brieuc Bay. The number refers to the individual within the population. The following letter(s) refer to the size of the mt genome: Ss, supershort; S, short; M, medium; I, intermediate; L, long; Sl, superlong. Heteroplasmy is observed for B6, which carries Ss and S genomes (Table 2 and Rigaa et al., 1993). Individuals for which data are missing (G1, G4, B10, B12 and S3) have not been taken into account.
Although mtDNA characteristics are useful for the study of phylogenetic relationships or population differentiation of species (Blot et al., 1990; Reeb \& Avise, 1990), the specific forces underlying the evolutionary changes of mtDNA (mutation, selection, founder effect and genetic drift) could be quite distinct from those acting on the nuclear genome. Thus patterns of mtDNA differentiation will not necessarily coincide with patterns of morphological and nuclear differentiations as shown by this study. Bonaud et al. (1994) have described an example of the discrepancy between taxa positions of large molluscan Cephalopoda based on morphological and mitochondrial DNA analyses.

Whatever the difference between allozyme and mtDNA, this study demonstrates that, from the point of view of stock discrimination in this species, mtDNA analysis is likely to be more useful than allozyme analysis. The rare variants observed for some endonucleases (see Table 2) constitute potential markers allowing the study of genetic characters and their interactions with local environmental factors and provide the possibility of restocking new localities.

Experiments involving the transfer of spat from the St Brieuc population scallops to other sites and farming them at least for more than one generation are required to assess the relative importance of genetic (bottlenecks, genetic drift, different selective forces acting on mtDNA genotypes) and environmental factors acting on the gametogenesis cycle. Also, the real absence of genetic discontinuity of $P$. maximus populations, as judged by mtDNA studies, suggests rather an adaptation of the Saint Brieuc population of scallops to the local ecological factors of this geographical area. Such an adaptation, characterized by the specific reproductive behaviour of this scallop population, is not apparently accompanied by allozyme polymorphism or by mtDNA variation. Furthermore, the interaction of genetic and environmental factors (temperature, food and salinity) and their influences on the gametogenesis cycle for different scallop species is still poorly understood and may fluctuate among different populations of the same species (Latrouite \& Claude, 1979; Barber \& Blake, 1991).

\section{Acknowledgements}

We are grateful to Paul Henry for fishing scallop from the Glénan Islands and all the members of the 'Laboratoire de Biologie marine' in Concarneau. Thanks are due to Mark Kelleher for English reading of the manuscript. 


\section{References}

AVISE, J. C. 1991. Ten unorthodox perspectives on evolution prompted by comparative population genetic findings on mitochondrial DNA. Ann. Rev. Genet., 25, $45-69$.

AVISE, J. C., LANSMAN, R. A. AND SHADE, R. O. 1979. The use of restriction endonucleases to measure mitochondrial DNA sequence relatedness in natural populations. I. Population structure and evolution in the genus Peromycsus. Genetics, 92, 279-295.

AVISE, J. C., ARNOLD, J., BALL, R. M., BERMINGHAM, E., LAMB, T., NEIGEL, J. E. ET AL. 1987. Intraspecific phylogeography: the mitochondrial DNA bridge between population genetics and systematics. Ann. Rev. Ecol. Syst., 18, 489-522.

BARBER, B. J. AND BLAKE, N. J. 1991. Reproductive physiology. In: Shumway, S. E. (ed.) Scallops: Biology, Ecology and Aquaculture, Developments in Aquaculture and Fisheries Science, Vol. 21, pp. 377-428. Elsevier, Amsterdam.

BEAUMONT, A. R.. 1991. Allozyme data and scallop stock identification. J. COns. Int. Mer, 47, 333-338.

BEAUMONT, A. R., MORVAN, C., HUELVAN, S., LUCAS, A. AND ANSELL, A. D. 1993. Genetics of indigenous and transplanted populations of Pecten maximus: no evidence for the existence of separate stocks. J. Exp. Mar. Biol. Ecol., 169, 77-88.

BLOT, M., LEGENDRE, B. AND ALBERT, P. 1990. Restriction fragment length polymorphism of mitochondrial DNA in subantarctic mussels. J. Exp. Mar. Biol. Ecol., 141, 79-86.

BONNAUD, L., BOUCHER-RODONI, R. AND MONNEROT, M. 1994. Phylogeny of decapod cephalopods based on partial 16S rDNA nucleotide sequences. C. r. Acad. Sci. Paris, 317, 581-588.

BOULDING, E. G., BOOM, J. D. G. AND BECKENBACH, A. T. 1993. Genetic variation in one bottlenecked and two wild populations of the Japanese scallop (Patinopecten yessoensis): empirical parameter estimates from coding regions of mitochondrial DNA. Can. J. Fish Aquat. Sci., 50, 1147-1157.

COCHARD, נ. C. AND Devauchelle, N. 1993. Spawning fecundity and larval survival and growth in relation to controlled conditioning in native and transplanted populations of Pecten maximus (L.): evidence for the existence of separate stocks. J. Exp. Mar. Biol. Ecol., $169,41-56$.

FISHER, C. AND SKIBINSKI, D. O. F. 1990. Sex-biased mitochondrial DNA heteroplasmy in the marine mussel Mytilus. Proc. R. Soc., B., 242, 149-156.

Glles, R. E., Bl.ANC, H., CANN, H. M. AND Wallace, D. C. 1980. Maternal inheritance of human mitochondrial DNA. Proc. Natl. Acad. Sci. U.S.A., 77, 6715-6719.

GJETVAJ, B., COOK, D. I. AND ZOUROS, E. 1992. Repeated sequences and large-scale size variation of mitochondrial DNA: a common feature among Scallops (Bivalvia: Pectinidae). Mol. Biol. Evol., 9, 106-124.

HOEH, W., BLAKLEY, K. H. AND BROWN, W. M. 1991. Hetero- plasmy suggests limited biparental inheritance of Mytilus mitochondrial DNA. Science, 251, 1488-1490.

KARAKAUSIS, Y. AND SKIBINSKI, D. O. F. 1992. An analysis of allozyme, mitochondrial DNA and morphological variation in mussel (Mytilus galloprovincialis) populations from Greece. Experientia, 48, 878-818.

LATROUITE, D. AND ClaUde, s. 1979. Essai de la culture de la coquille Saint Jacques Pecten maximus: influence de la transplantation sur le developpement gonadique. $I$. C. E. S., C.M. 1979/F, 16.

MACKIE, L. A. AND ANSEll, A. D. 1993. Differences in reproductive ecology in natural and transplanted populations of Pecten maximus: evidence for the existence of separate stocks. J. Exp. Mar. Biol. Ecol, 169, 57-75.

MONNEROT, M., SOLIGNAC, M. AND WOLSTENHOLME, D. R. 1990. Discrepancy in divergence of the mitochondrial and nuclear genomes of Drosophila teissieri and Drosophila yakuba. J. Mol. Evol., 30, 500-508.

NEI, M. AND MILleR, J. C. 1990. A simple method for estimating average number of nucleotide substitutions within and between populations from restriction data. Genetics, 125, 873-879.

PAULET, Y. M., LUCAS, A. AND gerard, A. 1988. Reproduction and larval development in two Pecten maximus (L.) populations from Brittany. J. Exp. Mar. Biol. Ecol., 119, $145-156$.

REEB, A. C. AND AVISE, J. C. 1990. A genetic discontinuity in a continuously distributed species: mitochondrial DNA in the American Oyster, Crassostrea virginica. Genetics, 124, 397-406.

REPIN, P. V. AND BRYKOV, V. A. 1993. Mitochondrial DNA from sea scallops (Pectinidae) with unusual properties. Genetika, 29, 460-467.

RIGAA, A. 1994. Caractérisation Moléculaire du Génome Mitochondrial de Pecten maximus. Ph.D. thesis, Université Paris-Sud, UFR scientifique d'Orsay.

RIGAA, A., MONNEROT, M., LE GAL, Y. AND SELLOS, D 1993. Mapping and repeated sequence organization of mitochondrial DNA in scallop, Pecten maximus. Mol. Mar. Biol. Biotech., 2, 4, 218-224.

RIGAA, A., MONNEROT, M. AND SELLOS, D. 1995. Molecular cloning and complete nucleotide sequence of the repeated unit and flanking gene of the scallop Pecten maximus mitochondrial DNA: putative replication origin features. J. Mol. Evol, , 41, 189-195.

SKIBINSKI, D. O. F., GALLAGHER, C. AND BEYNON, C. M. 1994. Sex-limited mitochondrial transmission in the marine mussel Mytilus edulis. Genetics, 138, 801-809.

SOligNAC, M., MONNEROT, M. AND MOUNOLOU, J.-C. 1986. Concerted evolution of sequence repeats in Drosophila mitochondrial DNA. J. Mol. Evol., 24, 53-60.

SWOFFORD, D. L. 1990. PAUP: Phylogenetic Analysis Using Parsimony, Version 3.0. Computer program distributed by the Illinois Natural History Survey, Champaign, IL.

zoUros, E., FREEMAN, K. R., BALl, A. O. AND POGSON, G. H. 1992. Direct evidence for extensive paternal mitochondrial DNA inheritance in the marine mussel Mytilus. Nature, 359, 412-414. 
ZOUROS, E., BALl, A. O., SAAVEDRA, C. AND FREEMAN, K. R. 1994a. An unusual type of mitochondrial DNA inheritance in the blue mussel Mytilus. Proc. Natl. Acad. Sci. U.S.A., 91, 7463-7467.
ZOUROS, E., BALL, A. O., SAAVEDRA, C. AND FREEMAN, K. R. 1994b. Mitochondrial DNA inheritance. Nature, 363, 817-818. 